\title{
Eu3+-Activated NaGdF4 Nanorods for Near-Ultraviolet Light-Triggered Indoor Illumination
}

\author{
Peng Du ${ }^{a b^{\dagger^{*}}}$, Weiguang Ran ${ }^{c \dagger}$, Yafei Hou ${ }^{\text {ab }}$, Laihui $\mathbf{L u o}^{\text {ab }}{ }^{*}$ and Weiping $\mathbf{L i}^{\text {ab }}$ \\ ${ }^{a}$ Department of Microelectronic Science and Engineering, Ningbo University, 315211 Ningbo, China \\ ${ }^{b}$ Department of Physical Science and Technology, Ningbo University, 315211 Ningbo, China \\ ${ }^{c}$ Department of Physics, Pukyong National University, Busan 608-737, South Korea
}

Corresponding authors:

E-mail: dupeng@nbu.edu.cn (P. Du); luolaihui@nbu.edu.cn (L. Luo)

P. Du and W. Ran contributed equally to this work.

Table S1. Refined structural parameters for the $\mathrm{NaGdF}_{4}: 0.5 \mathrm{Eu}^{3+}$ nanorod.

\begin{tabular}{lccccccccc}
\hline Phase structure & $a=b(\AA)$ & $c(\AA)$ & $V\left(\AA^{3}\right)$ & $\alpha=\beta$ & $\gamma$ & $R_{\mathrm{p}}$ & $R_{\mathrm{wp}}$ & $\chi^{2}$ & $\mathrm{Z}$ \\
\hline Hexagonal & 6.021834 & 3.665239 & 115.104 & $90^{\circ}$ & $120^{\circ}$ & $4.89 \%$ & $6.23 \%$ & 1.646 & 1 \\
\hline
\end{tabular}

Table S2. Wavenumbers and transition rates for the ${ }^{5} \mathrm{D}_{0} \rightarrow{ }^{7} \mathrm{~F}_{\mathrm{J}}(\mathrm{J}=1,2,3,4)$ of $\mathrm{Eu}^{3+}$ ions in $\mathrm{NaGdF}_{4}: 0.5 \mathrm{Eu}^{3+}$ nanorods.

\begin{tabular}{lccc}
\hline Transition & Type & Wavenumber $\left(\mathrm{cm}^{-1}\right)$ & Transition rate $\left(\mathrm{s}^{-1}\right)$ \\
\hline${ }^{5} \mathrm{D}_{0} \rightarrow{ }^{7} \mathrm{~F}_{1}$ & Magnetic dipole & 16863.41 & 58.22 \\
${ }^{5} \mathrm{D}_{0} \rightarrow{ }^{7} \mathrm{~F}_{2}$ & Electric dipole & 16233.77 & 175.36 \\
${ }^{5} \mathrm{D}_{0} \rightarrow{ }^{7} \mathrm{~F}_{3}$ & Forbidden & 15408.32 & 1.88 \\
${ }^{5} \mathrm{D}_{0} \rightarrow{ }^{7} \mathrm{~F}_{4}$ & Electric dipole & 14367.82 & 38.50 \\
\hline
\end{tabular}


Table S3. Chromaticity parameters of the fabricated WLEDs device as a function of forward bias current.

\begin{tabular}{lcccc}
\hline Current & $x$ & $y$ & CCT & CRI \\
\hline $50 \mathrm{~mA}$ & 0.343 & 0.353 & $5091 \mathrm{~K}$ & 86.2 \\
$100 \mathrm{~mA}$ & 0.337 & 0.350 & $5303 \mathrm{~K}$ & 86.6 \\
$150 \mathrm{~mA}$ & 0.331 & 0.347 & $5553 \mathrm{~K}$ & 87.2 \\
$200 \mathrm{~mA}$ & 0.328 & 0.346 & $5674 \mathrm{~K}$ & 87.5 \\
$250 \mathrm{~mA}$ & 0.325 & 0.344 & $5821 \mathrm{~K}$ & 87.8 \\
\hline
\end{tabular}



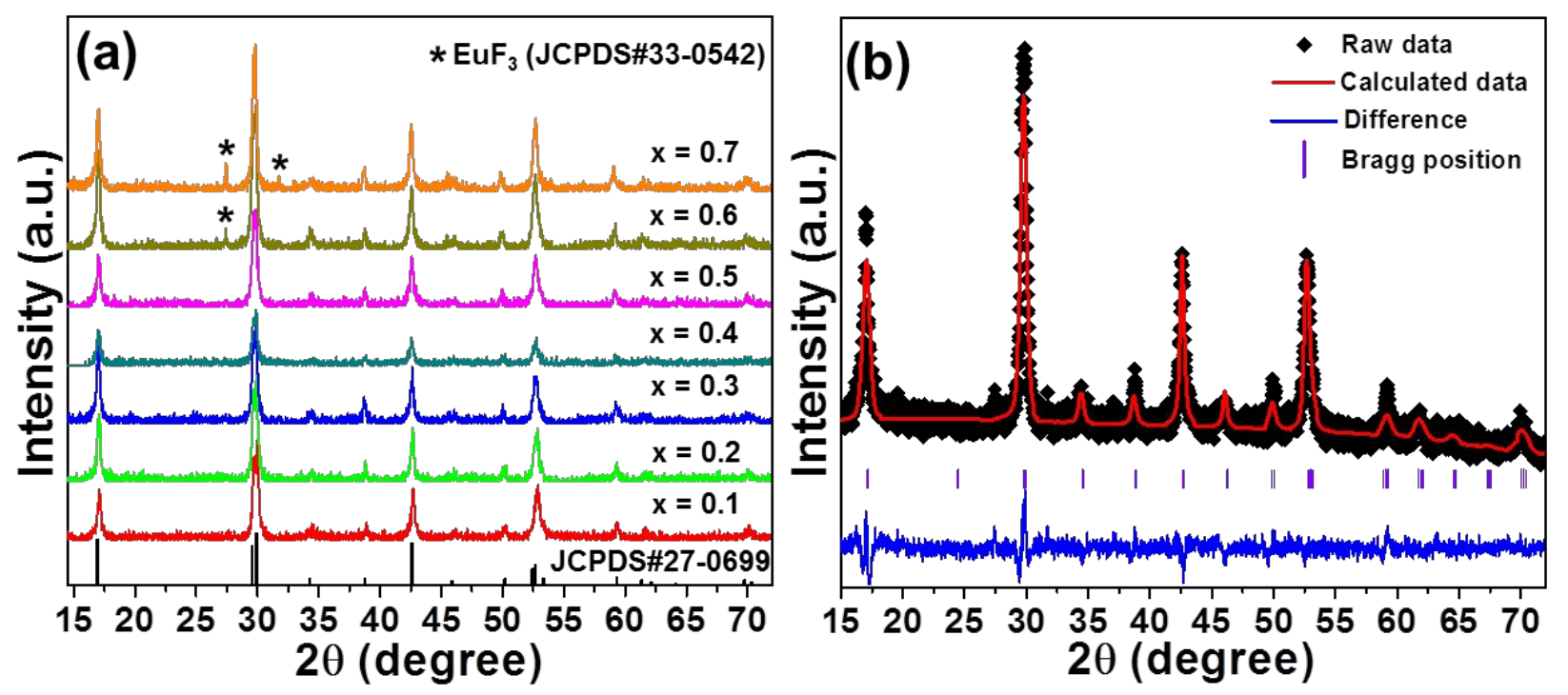

Figure S1. (a) XRD patterns of $\mathrm{NaGdF}_{4}: x \mathrm{Eu}^{3+}(x=0.1,0.2,0.3,0.4,0.5,0.6,0.7)$ nanorods. (b) Rietveld XRD refinement pattern of the $\mathrm{NaGdF}_{4}: 0.5 \mathrm{Eu}^{3+}$ nanorod. 


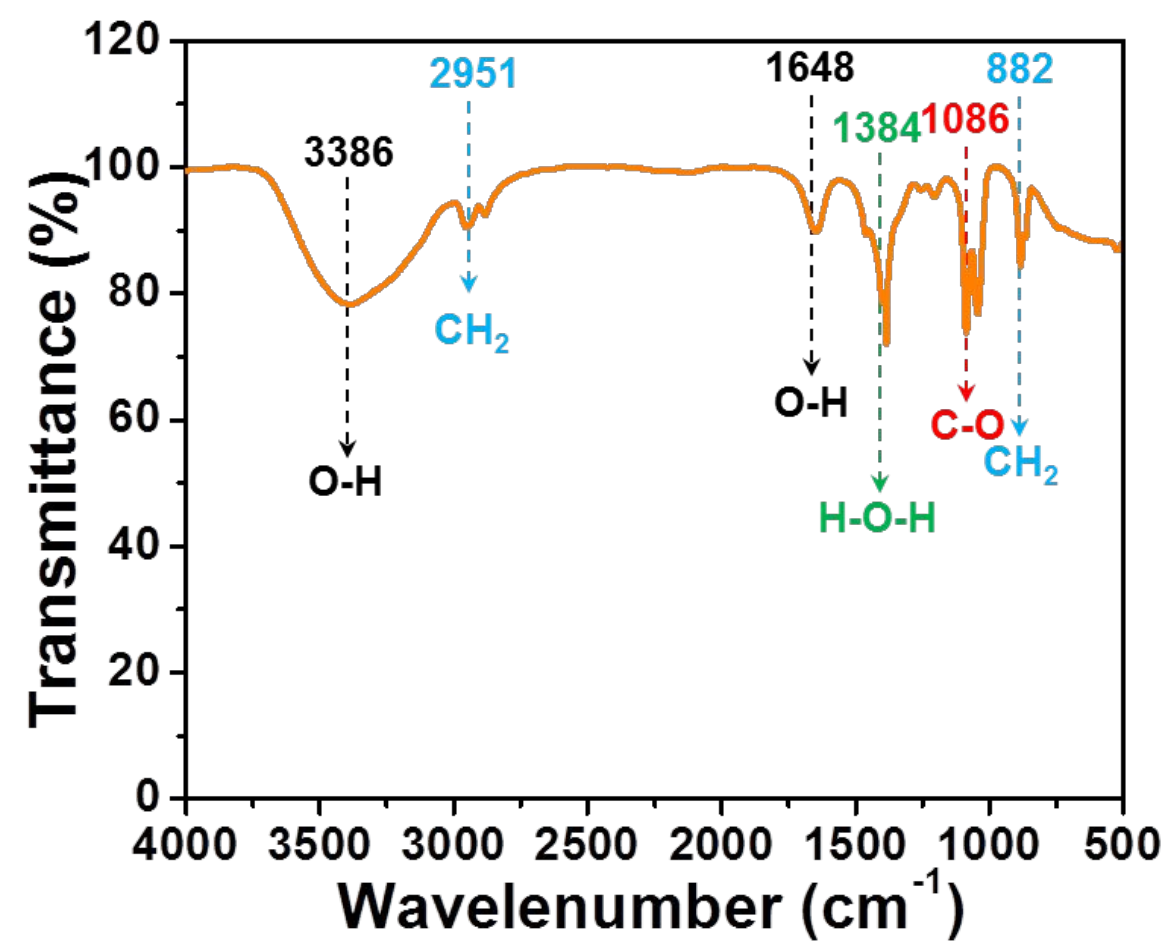

Figure S2. FT-IR spectrum of $\mathrm{NaGdF}_{4}: 0.5 \mathrm{Eu}^{3+}$ nanorod in the range of $500-4000 \mathrm{~cm}^{-1}$. 


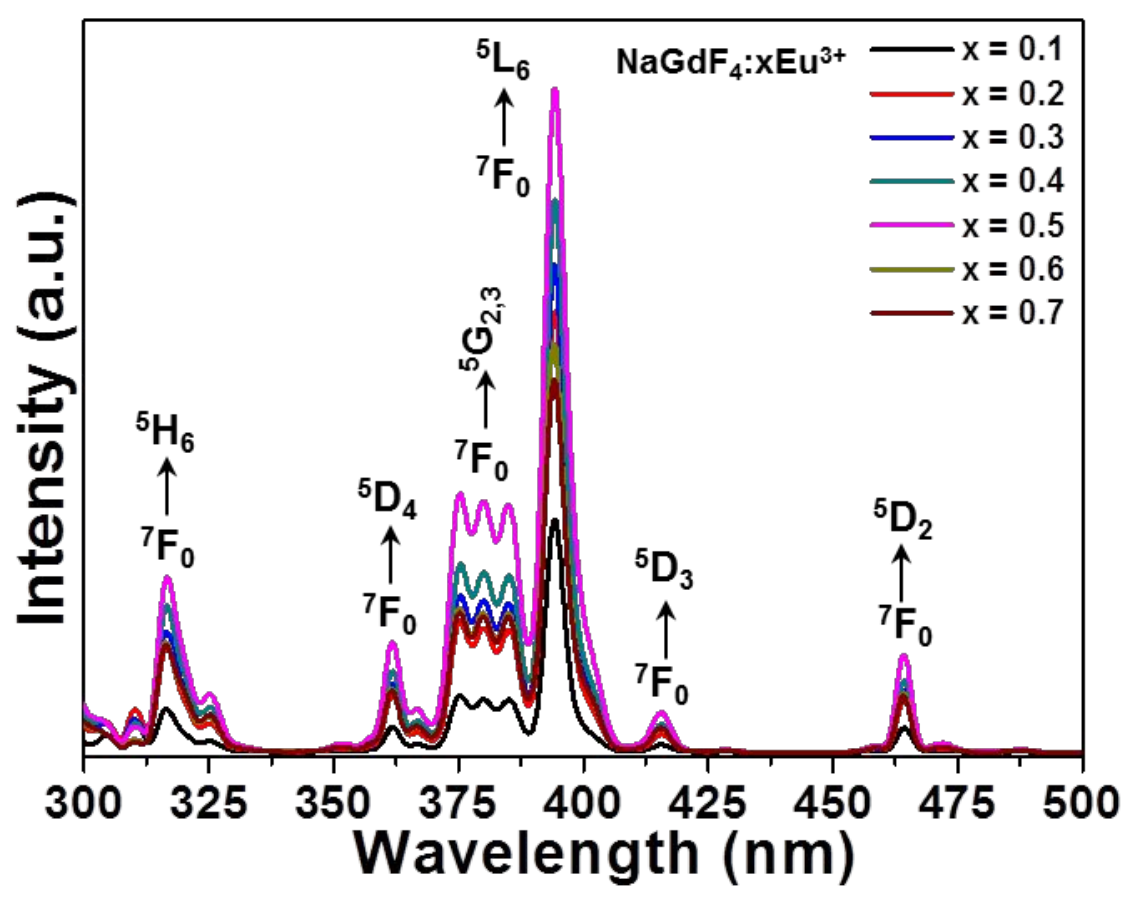

Figure S3. Excitation spectra of the $\mathrm{Eu}^{3+}$-activated $\mathrm{NaGdF}_{4}$ nanorods with different dopant concentrations. 


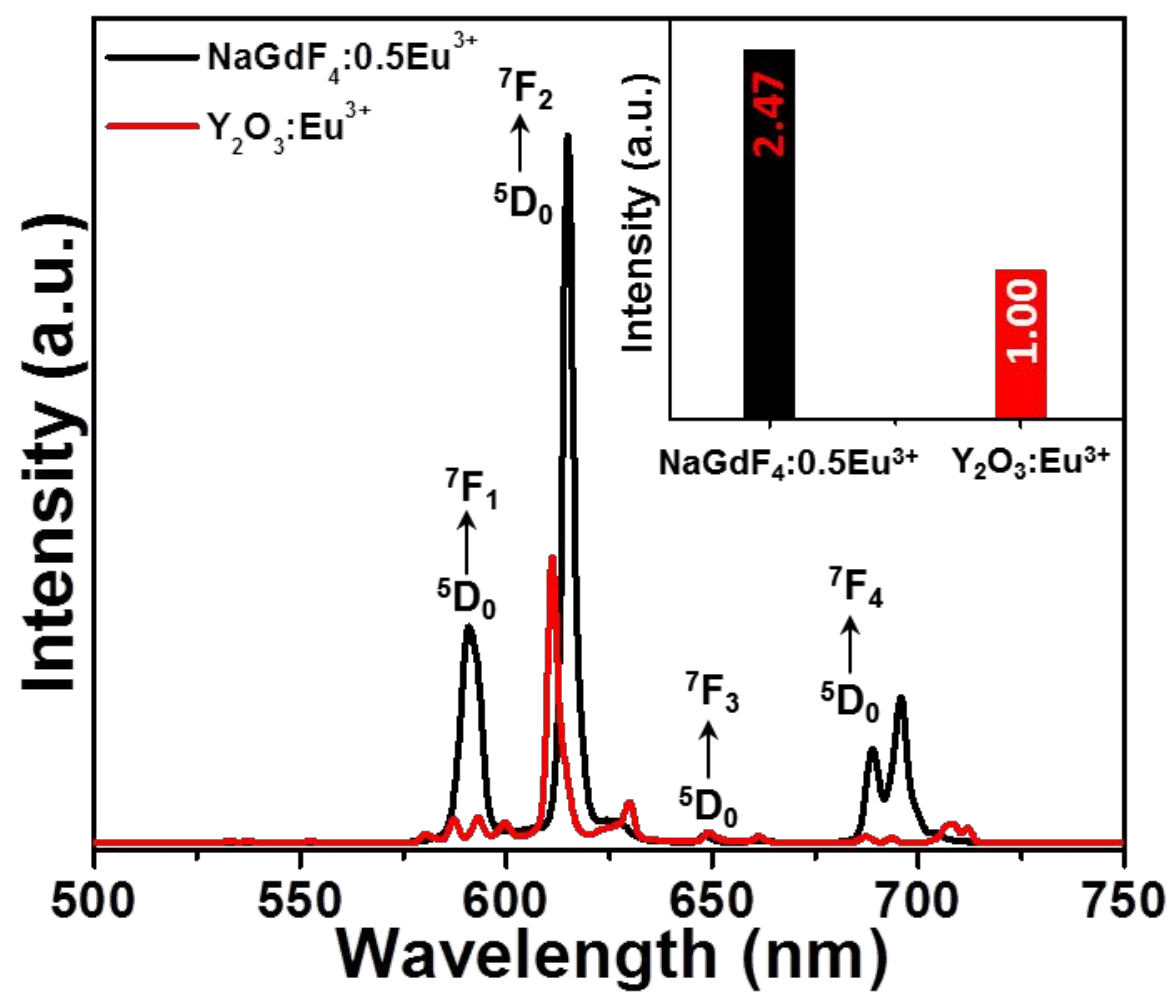

Figure S4. Comparison of emission spectra between the $\mathrm{NaGdF}_{4}: 0.5 \mathrm{Eu}^{3+}$ nanorods and commercial $\mathrm{Y}_{2} \mathrm{O}_{3}: \mathrm{Eu}^{3+}$ red emitting phosphors excited at $396 \mathrm{~nm}$. Inset shows the relative emission intensities between the $\mathrm{NaGdF}_{4}: 0.5 \mathrm{Eu}^{3+}$ nanorod and commercial $\mathrm{Y}_{2} \mathrm{O}_{3}: \mathrm{Eu}^{3+}$ red emitting phosphors. 


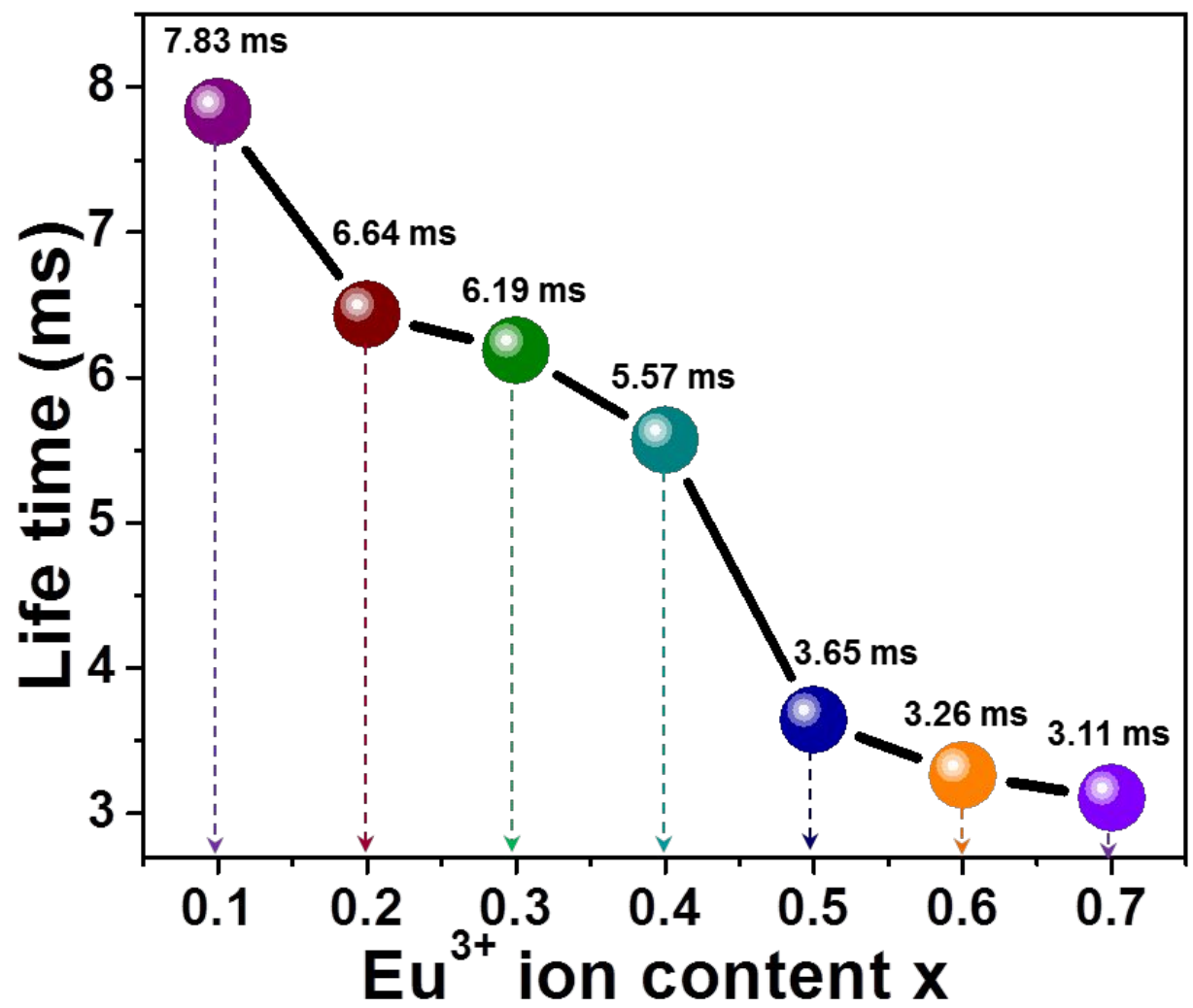

Figure S5. Life time for the ${ }^{5} \mathrm{D}_{0}$ level of $\mathrm{Eu}^{3+}$ ions in the $\mathrm{NaGdF}_{4}: x \mathrm{Eu}^{3+}$ nanorods as function of dopant concentration. 


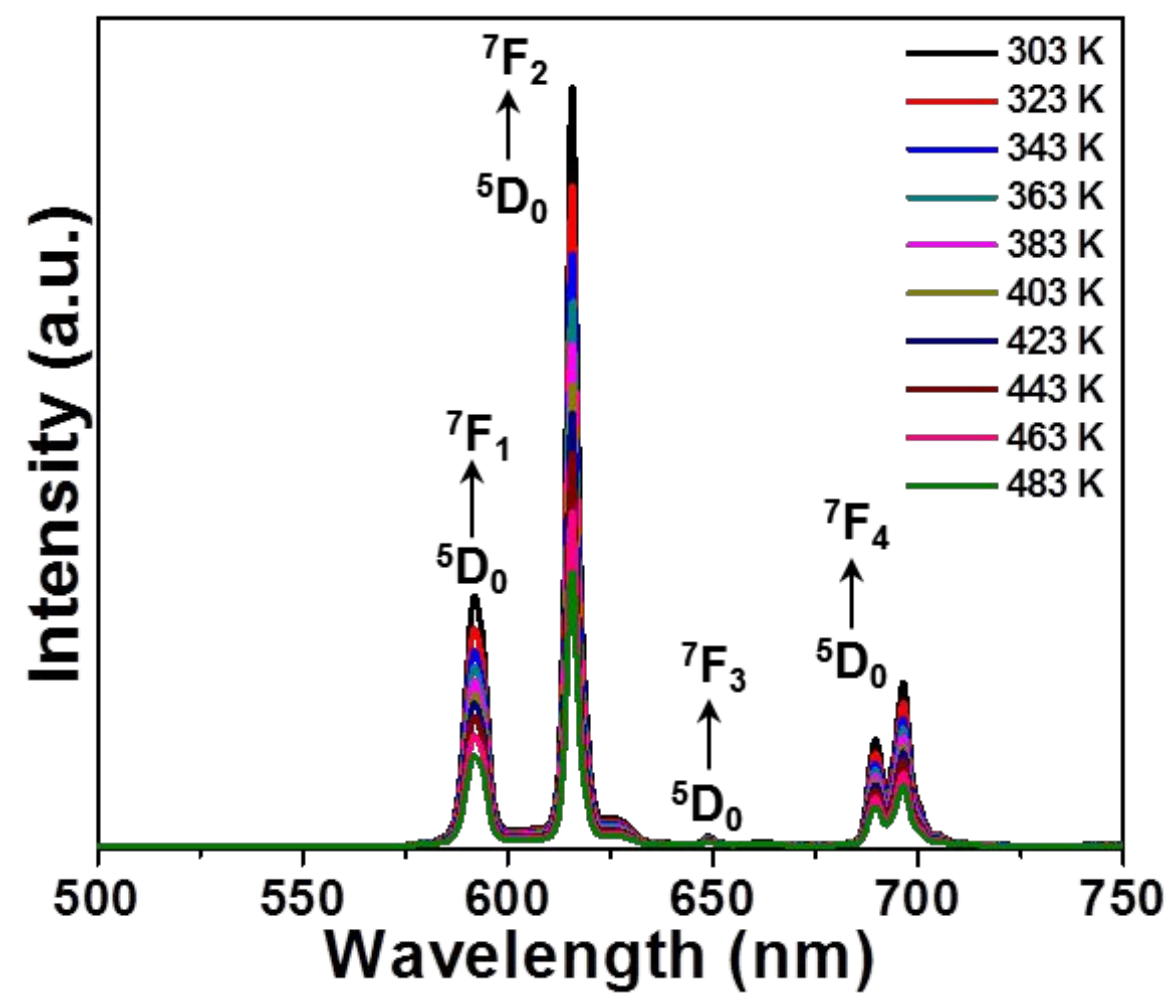

Figure S6. PL emission spectra of the $\mathrm{NaGdF}_{4}: 0.5 \mathrm{Eu}^{3+}$ nanorod as a function of temperature. 


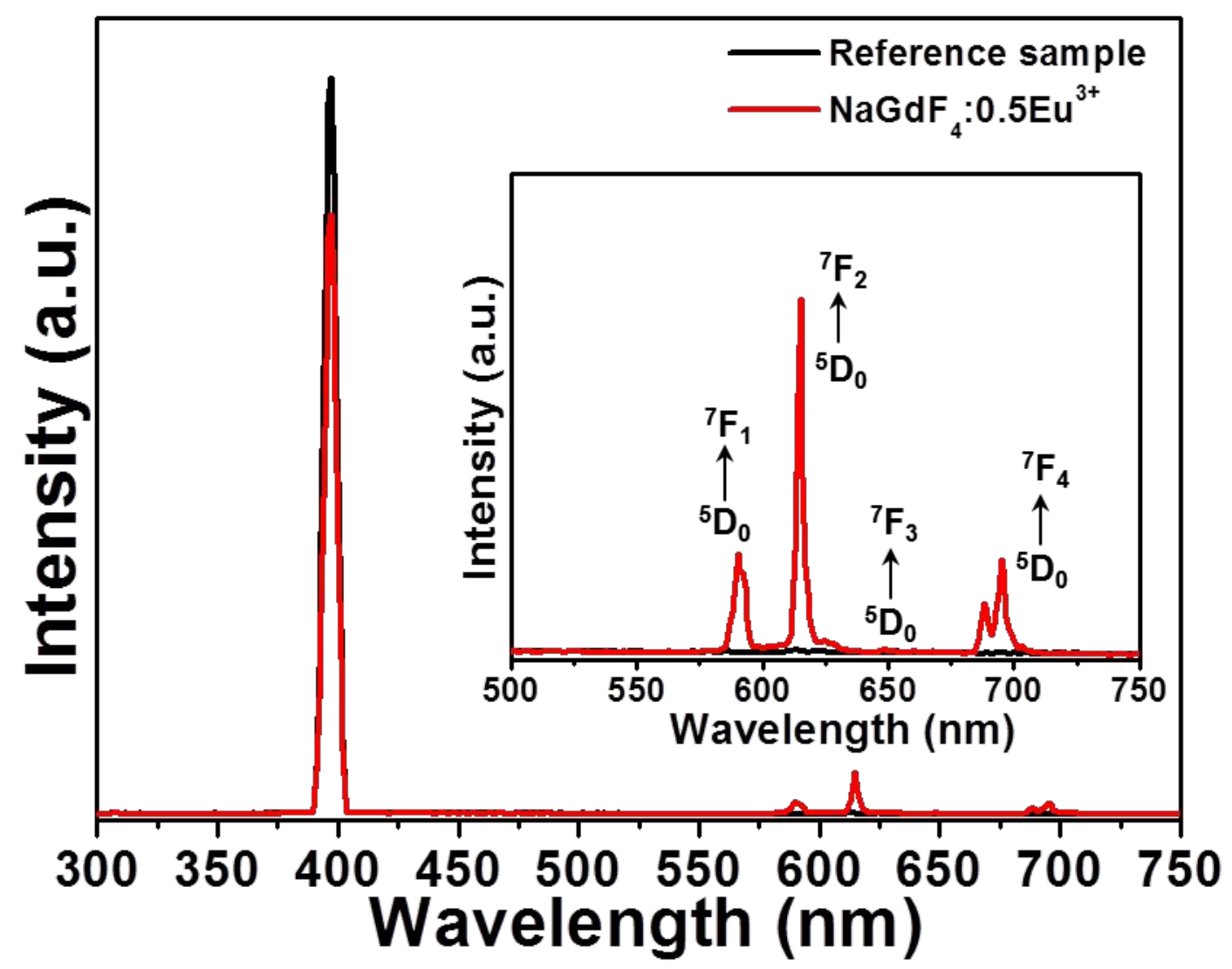

Figure S7. PL excitation and emission spectra of the NaGdF4:0.5 $\mathrm{Eu}^{3+}$ nanorod and reference sample, measured by using a spectrofluorometer attached with an integrating sphere for quantum efficiency measurement. Inset illustrates the zoomed emission spectra in the wavelength range of $500-750 \mathrm{~nm}$. 

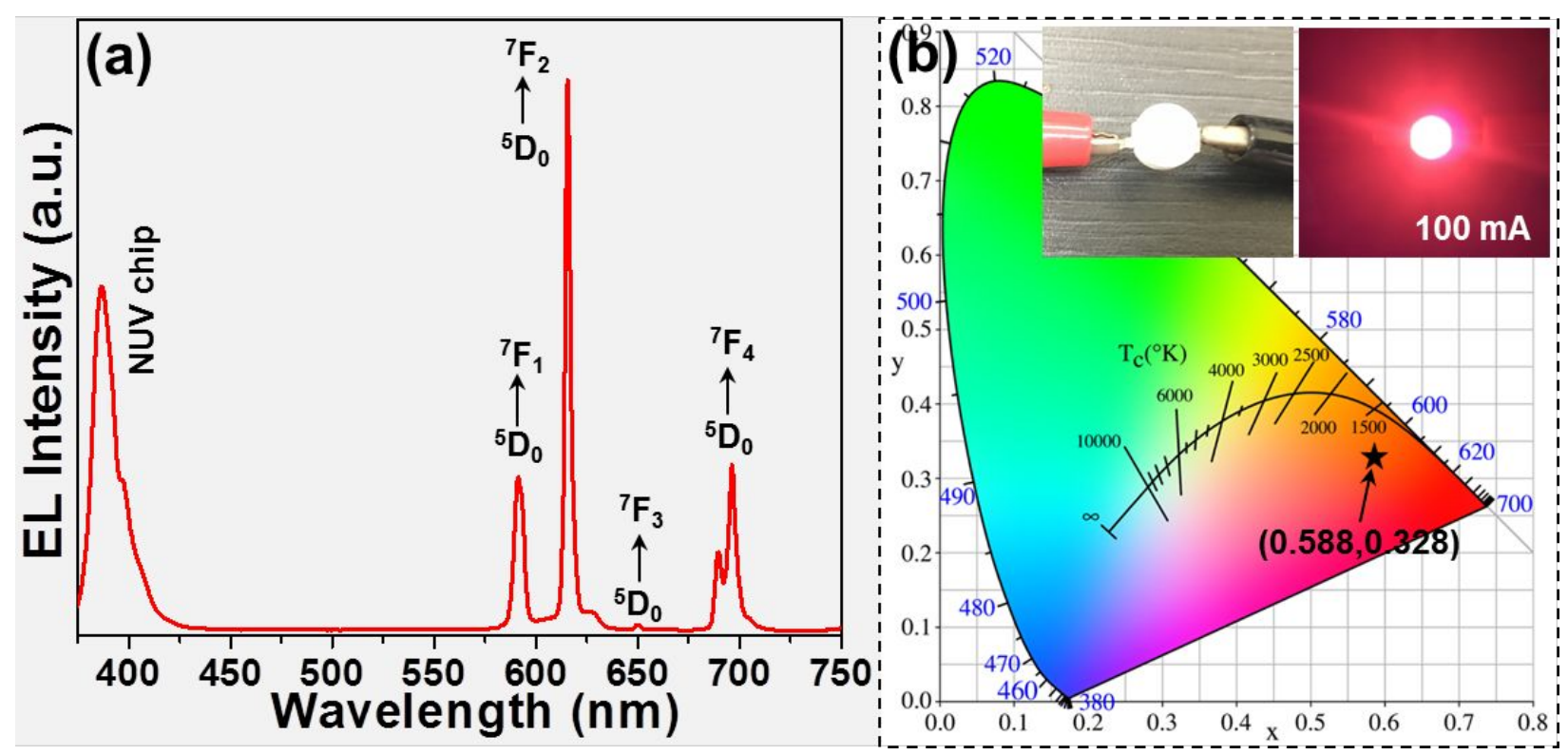

Figure S8. (a) EL emission spectrum of the developed red-emitting LED device. (b) CIE chromaticity diagram of the developed red-emitting LED device. Inset shows the luminescent images of the developed LED device without and with injection current. 


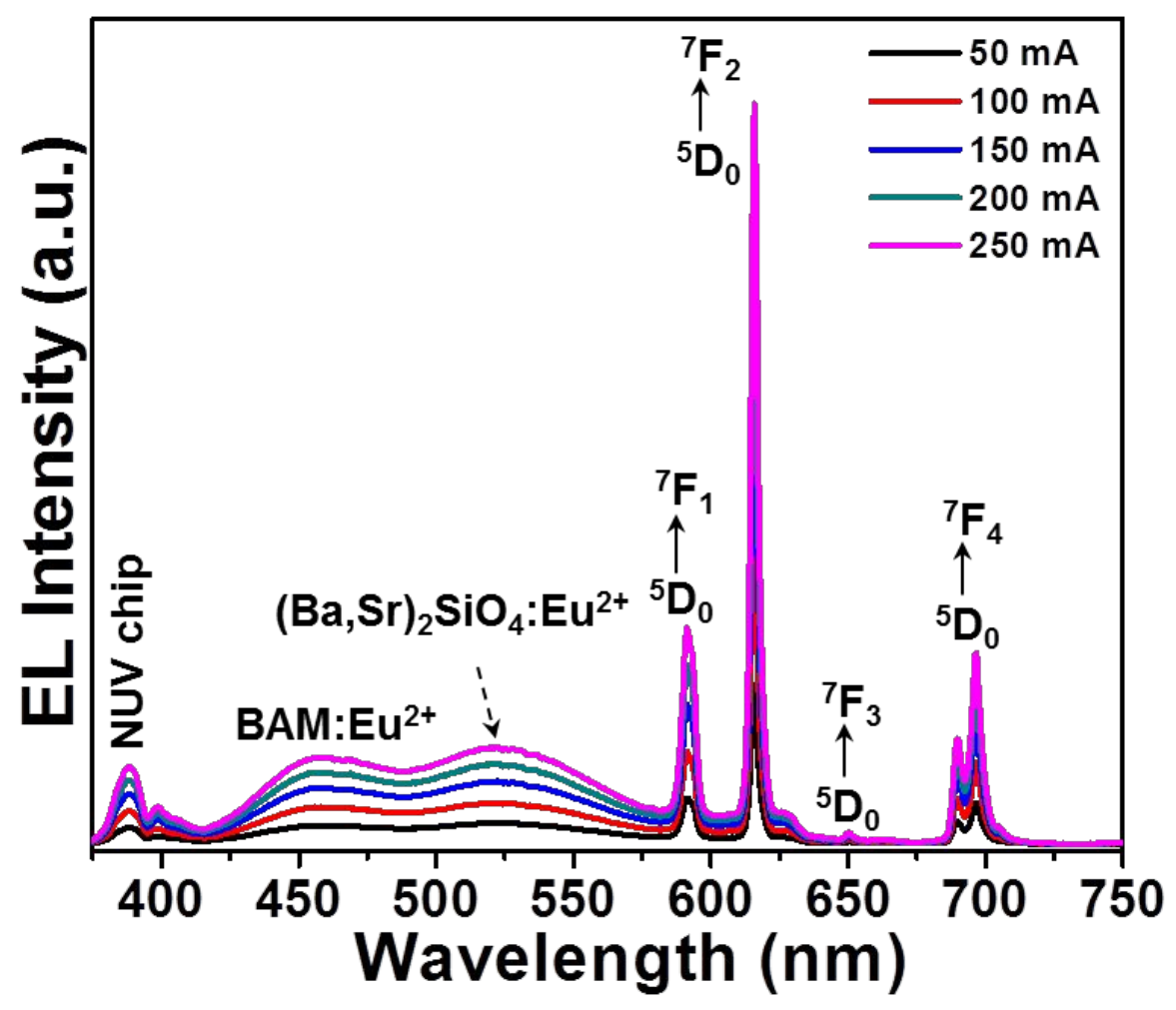

Figure S9. EL emission spectra of synthesized WLEDs device as a function of forward bias current. 